Environmental Atmospheric Sciences and Air Pollution

\title{
The Current State of the Problem of Using Landscape Indicators to Assess Soil and Ground Conditions in the Mountainous Regions of the Chechen Republic
}

\author{
$\underline{\text { Abdul Abumuslimov }}^{1,2}$, Musa Taisumov $^{1}$, Fazil Alakhverdiyev ${ }^{1}$, Indira Abumuslimova ${ }^{1}$ \\ ${ }^{1}$ Chechen State University, 32, A. Sheripov Street, 364907, Grozny, Russia \\ ${ }^{2}$ Academy of Sciences of the Chechen Republic, 13, M. Esambaev Ave., 364024, Grozny, Russia
}

doi: https://doi.org/10.21467/abstracts.93.61

\begin{abstract}
The work discusses the issues of indicative landscape science aimed at the practical use of landscape components. It is shown that one of the important forms of landscape indication is the predictive indication of processes based on the results of retro-indication and stage-synchronous indication studies. It was revealed that the elements of the territorial morphological structure of the landscape as indicators are formed under the influence of certain causes of exogenous or endogenous processes. All elements that make up the natural environment of any part of the territory (rocks, water, relief, climate, soil, vegetation, wildlife and human activities) are closely interconnected with each other. The natural system, which is formed as a result of this relationship, is called the natural-territorial complex (NTC). Elements of the natural environment, as a result of the interaction of which NTC occurs, are called landscape components. According to existing ideas, in modern landscape science, the leading links in any landscape are climate and lithogenic basis, i.e. geological structure of the area and lithological composition of its constituent rocks. At the same time, each landscape has a certain external appearance, determined primarily by the components that we can directly observe - that is, relief and vegetation. Thus, the landscape takes on the character of a longline system.

The deepest tier is the lithogenic base, tiers lie higher - formed by the subsoil and soil, and all this is supported by the upper tier visible by us, in the addition of which the surface forms of the relief, aboveground tiers of vegetation and the soil surface take part. Such components of the landscape as the relief and vegetation that form the ectoyar are the most easily accessible for observation and, as it were, form the external appearance, physiognomy of the landscape. Most of the components of the lithogenic base - rocks and groundwater, especially tectonics - are not available for direct observation; in order to observe them, one has to resort to drilling, the construction of mine workings, or to look for separate disconnected outcrops. Such components of the landscape that are inaccessible to observation are called recipient. Most definitely, in terms of accessibility for direct observation, the position of such an important component as soil. Wherever the vegetation cover is closed, the soil belongs to the recipient components, where the integrity is absent.

The close connection of all the NTC components and the dependence of the distribution of physiognomic components on the recipient components allows the determination of difficultly observed, recipient components by the physiognomic components that are part of the ektofloor and are easily accessible for observation. The theory and practice of such studies are studied in a special section of the doctrine of landscape. Methods based on the use of the external appearance of the terrain to determine soils, rocks, groundwater, as well as climatic conditions, are called landscape-indicating methods. One of the most important means of landscape-indicating methods is the interpretation of aerial photographs and aero-visual observations, since using these research methods it is possible to characterize the appearance of the
\end{abstract}

C 2020 Copyright held by the author(s). Published by AIJR Publisher in "Abstracts of The Second Eurasian RISK-2020 Conference and Symposium" April 12- 19, 2020, Tbilisi, Georgia. Jointly organized by AMIR Technical Services LLC, Georgian Technical University, Institute of Geography (Kazakhstan) and Russian Institute of Petroleum Geology and Geophysics.

DOI: $10.21467 /$ abstracts.93 
The Second Eurasian RISK-2020 Conference and Symposium

landscape with the most completeness and accuracy and reveal its relationship with geological and hydrogeological conditions.

In aero-landscape indication a certain terminology has been developed. So the object of indication or indicator is called the recipient component for the purpose of which the indication is made. The physiognomic components used for indication are called indicators; as their most often various combinations of relief and vegetation appear, caused by complex or landscape indicators; if relief forms are used for indication, then they are called geomorphological indicators; if the indication is made by plant communities - about geobotanical indicators. Among the indicators, direct and indirect ones are distinguished. Direct indicators are those that have a direct relationship with the indicator and depend on its distribution. Indirect indicators are those whose relationship with the indicator is through some intermediate link in the environment. Direct indicators are very stable and change little in different parts of the range, while indirect indicators are usually regional in nature. By the nature of the object, indicative studies conducted in the mountainous areas are divided into hydroindication, pedoindication, lithoindication and indication of minerals. For the practice of agricultural assessment of the territory, pedo-indicator and litho-indicator studies are of the greatest importance. Initially, in the mountainous regions, only a geobotanical indication took place. At the same time, the work had a predominant litho-indicative character. Indication of soils as an independent task was not posed.

In most non-indicative works, it was not the relationship between vegetation and soil that was studied, but the relationship between vegetation and rock. The main modern directions in indicator research in mountainous areas are: a) the development of landscape indication when used as indicators of both landforms and their exposure and vegetation; b) the use of landscape indications to determine exogenous processes in the mountains; c) further development of litho-indication and refinement of its methodology. Further development of this area of research in the laboratory and VSEGINGEO methods under the direction of A.V. Sadova led to the formation of a concept according to which the development of exogenous processes in the mountains can be predicted based on landscape indications. In this case, the starting link is the compilation of a landscape map, which is then interpreted for indicative purposes. Interpretation is carried out by identifying which of the selected landscapes are characterized by certain exogenous processes. This identification is carried out by studying in the field key areas selected within different landscapes, as well as by viewing aerial photographs and fixing manifestations of various processes on them. 